See Article page 1791.

\section{Commentary: Advanced assessments of flow velocity to optimize surgical repair and clinical outcomes in single-ventricle congenital heart disease}

\author{
Christoph P. Hornik, MD, PhD, MPH
}

Schäfer and colleagues ${ }^{1}$ share findings from their singlecenter four-dimensional magnetic resonance imaging (4DMRI) evaluation of 26 patients with palliated hypoplastic left heart syndrome investigating the influence of neoaortic arch tapering on flow-mediated viscous energy loss and the correlation between flow-geometry and single-ventricle power generation. They found that patients with higher degree of neoaortic arch tapering experienced more than 2-fold greater viscous energy loss. Although this represents irreversibly wasted power generated by the single ventricle, a situation that should clearly be avoided, viscous energy loss accounted for only $0.7 \%$ and $0.3 \%$ of generated ventricular power in patients with high and low degrees of aortic arch tapering, respectively.

This innovative study adds to the current body of literature highlighting the potentially negative consequences of oversized ascending aortas following Norwood palliation: increased pulse wave velocity, altered reflections in distal vasculature, and increased aortic stiffness have been negatively associated with ventricular performance. Schäfer and colleagues' 1 study is the first to comprehensively explore fluid dynamics in altered neoaortic morphologies following Norwood palliation using 4D-MRI. The

\footnotetext{
From the Department of Pediatrics and Duke Clinical Research Institute, Duke University School of Medicine, Durham, NC.

Disclosures: The author reported no conflicts of interest.

The Journal policy requires editors and reviewers to disclose conflicts of interest and to decline handling or reviewing manuscripts for which they may have a conflict of interest. The editors and reviewers of this article have no conflicts of interest.

Received for publication March 5, 2021; revisions received March 5, 2021; accepted for publication March 8, 2021; available ahead of print March 11, 2021.

Address for reprints: Christoph P. Hornik, MD, PhD, MPH, Department of Pediatrics and Duke Clinical Research Institute, Duke University School of Medicine, $301 \mathrm{~W}$ Morgan St, Durham, NC 27701 (E-mail: christoph.hornik@dm.duke.edu).

J Thorac Cardiovasc Surg 2021;162:1809-10

$0022-5223 / \$ 36.00$

Copyright (C) 2021 by The American Association for Thoracic Surgery

https://doi.org/10.1016/j.jtcvs.2021.03.023
}

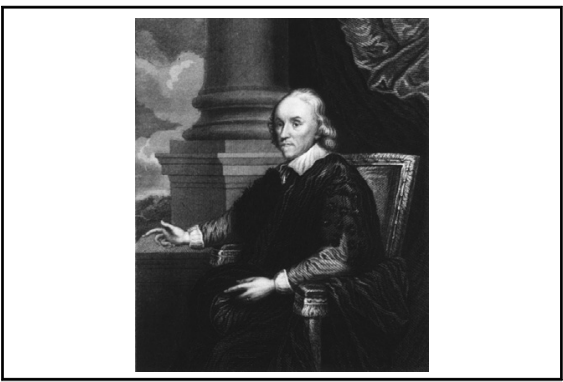

William Harvey (1578-1657), the English physician credited with recognizing human circulation.

\section{CENTRAL MESSAGE \\ 4D-MRI evaluation of ascending aortic flow after Norwood palli- ation identifies higher viscous energy loss with greater degree of neo-aortic tapering.}

application of this method, which allows for true in vivo determination of flow velocities, rather than relying on simplified flow velocity measurements obtained from traditional MRI or echocardiography, has the potential to significantly change our approach to assessing the hemodynamic consequences of inherent or residual cardiac lesions. The technique has found applications in adult patients with arterial, venous, and cardiac valve pathology assessments. ${ }^{2-5}$ In children with congenital heart disease, 4D-MRI has been used to assess proximal aortic flow dynamics following aortic valve surgery, tetralogy of Fallot repair, and the Fontan procedure. ${ }^{6-12}$ Beyond assessment of a patient's current hemodynamic state, 4D-MRI may also be applied to preoperative hemodynamic modeling of expected velocities and pressure gradients, although several limitations to these simulations remain. ${ }^{13,14}$ As with any new technology, population-specific limitations, technical considerations, inter- and intrarater reproducibility, and cost-effectiveness considerations deserve consideration. Technical aspects in particular play an important role in the appropriate acquisition of both 4D-MRI data and its interpretation. ${ }^{15}$ As is often the case, these limitations and considerations are less well defined in children with congenital heart disease. Ultimately, the importance of any new medical technology is measured by its influence on clinical care. Given the persistent clinical vulnerability of patients with single-ventricle congenital heart disease, 
4D-MRI has the potential for significant influence on their outcomes.

\section{References}

1. Schäfer M, Di Maria MV, Jaggers J, Stone ML, Ivy DD, Barker AJ, et al. Highdegree Norwood neoaortic tapering is associated with abnormal flow conduction and elevated flow-mediated energy loss. J Thorac Cardiovasc Surg. 2021;162: 1791-804.

2. Juffermans JF, Minderhoud SCS, Wittgren J, Kilburg A, Ese A, Fidock B, et al Multicenter consistency assessment of valvular flow quantification with automated valve tracking in 4D flow CMR. JACC Cardiovasc Imaging. February 2, 2021 [Epub ahead of print].

3. Misaki K, Futami K, Uno T, Nambu I, Yoshikawa A, Kamide T, et al. Inflow hemodynamics of intracranial aneurysms: a comparison of computational fluid dynamics and 4D flow magnetic resonance imaging. J Stroke Cardiovasc Dis. 2021; 30:105685.

4. Ramaekers M, Adriaans BP, Juffermans JF, van Assen HC, Bekkers SCAM, Scholte AJHA, et al. Characterization of ascending aortic flow in patients with degenerative aneurysms: a 4D flow magnetic resonance study. Invest Radiol. March 1, 2021 [Epub ahead of print].

5. Roberts GS, François CJ, Starekova J, Roldán-Alzate A, Wieben O. Non-invasive assessment of mesenteric hemodynamics in patients with suspected chronic mesenteric ischemia using 4D flow MRI. Abdom Radiol (NY). February 6, 2021 [Epub ahead of print].

6. Isorni MA, Martins D, Ben Moussa N, Monnot S, Boddaert N, Bonnet D, et al. 4D flow MRI versus conventional 2D for measuring pulmonary flow after tetralogy of Fallot repair. Int J Cardiol. 2020;300:132-6.

7. Jacobs KG, Chan FP, Cheng JY, Vasanawala SS, Maskatia SA. 4D flow vs. 2D cardiac MRI for the evaluation of pulmonary regurgitation and ventricular volume in repaired tetralogy of Fallot: a retrospective case control study. Int J Cardiovasc Imaging. 2020;36:657-69.

8. Kamphuis VP, Elbaz MSM, van den Boogaard PJ, Kroft LJM, Lamb HJ, Hazekamp MG, et al. Stress increases intracardiac 4D flow cardiovascular magnetic resonance-derived energetics and vorticity and relates to $\mathrm{VO}(2)$ max in Fontan patients. J Cardiovasc Magn Reson. 2019;21:43.

9. Rijnberg FM, van Assen HC, Hazekamp MG, Roest AAW. Tornado-like flow in the Fontan circulation: insights from quantification and visualization of viscous energy loss rate using 4D flow MRI. Eur Heart J. 2019;40:2170.

10. Schäfer M, Barker AJ, Morgan GJ, Jaggers J, Stone ML, Browne LP, et al. Increased systolic vorticity in the left ventricular outflow tract is associated with abnormal aortic flow formations in Tetralogy of Fallot. Int J Cardiovasc Imaging. 2020;36:691-700.

11. Secinaro A, Milano EG, Ciancarella P, Trezzi M, Capelli C, Ciliberti P, et al. Blood flow characteristics after aortic valve neocuspidization in paediatric patients: a comparison with the Ross procedure. Eur Heart J Cardiovasc Imaging. February 7, 2021 [Epub ahead of print].

12. Vial J, Bouzerar R, Pichois R, Lhostis F, Raad O, Mathiron A, et al. MRI assessment of right ventricular volumes and function in patients with repaired Tetralogy of Fallot using kat-ARC accelerated sequences. AJR Am J Roentgenol. 2020;215:807-17.

13. Carberry T, Murthy R, Hsiao A, Petko C, Moore J, Lamberti J, et al. Fontan revision: presurgical planning using four-dimensional (4D) flow and threedimensional (3D) printing. World J Pediatr Congenit Heart Surg. 2019;10:245-9.

14. Hellmeier F, Brüning J, Sündermann S, Jarmatz L, Schafstedde M, Goubergrits L, et al. Hemodynamic modeling of biological aortic valve replacement using preoperative data only. Front Cardiovasc Med. 2020;7:593709.

15. Casciaro ME, Pascaner AF, Guilenea FN, Alcibar JI, Gencer U, Soulat G, et al. 4D flow MRI: impact of ROI size, angulation and spatial resolution on aortic flow assessment. Physiol Meas. February 10, 2021 [Epub ahead of print]. 